J. Gerlici, I.A. Shvedchikova, I.V. Nikitchenko, J.A. Romanchenko

\title{
INVESTIGATION OF INFLUENCE OF SEPARATOR MAGNETIC SYSTEM CONFIGURATION WITH PERMANENT MAGNETS ON MAGNETIC FIELD DISTRIBUTION IN WORKING AREA
}

\begin{abstract}
Purpose. To carry out research the influence of magnetic system configuration (shape and size of the permanent magnets) on magnetic field spatial distribution in working area of new structure design magnetic separator with active front surface by numerical methods. Methodology. We have applied the magnetic field numerical simulation for permanent magnets system in absence of electrical current in magnetostatic approximation. We have solved the problem by using finite element method. Research of permanent magnets cross-sectional shape influence made in the two-dimensional formulation using software package Elcut. Research of magnetic field induction spatial (three-dimensional) distribution in new construction magnetic separator working area is conducted using software package COMSOL Multiphysics 3.5a. Results. Magnetic flux density maximum in the immediate vicinity of permanent magnet surface provide magnets with spherical and trapezoidal cross-sectional shape. At a distance from pole surface, where the separation process working, magnetic field density produced by trapezoidal and spherical cross section magnets, substantially lower in comparison with rectangular magnets. Rectangular and rectangular with beveled corners cross-section shape magnets create approximately same magnetic field intensity not significantly different in weight. Analysis of the spatial distribution of magnetic field induction in the working area of a new construction magnetic separator has shown that a strong magnetic field with high magnetic flux density gradient value is formed in the interpolar working volume. Originality. For the first time research of magnetic flux density distribution in working area of new construction magnetic separator is conducted. Developed device feature is complex spatial distribution of magnetic field. Practical value. Results of research can be used for selection of rational parameters of separator magnetic system. Received results also can be used for determination of separator force characteristics. References 11, figures 8 .
\end{abstract}

Key words: magnetic separator, permanent magnet, magnetic field, finite element method.

В работе проведено исследование влияния конфигурации магнитной системы (формы и размеров постоянных магнитов) на пространственное распределение индукции магнитного поля в рабочей зоне магнитного сепаратора нового конструктивного исполнения. Поставленные задачи решены с использованием численного метода конечных элементов. Показано, что кольцевые постоянные магниты с прямоугольной формой поперечного сечения обеспечивают наиболее высокие показатели магнитной индукции в рабочих воздушных зазорах на требуемых расстояниях от поверхности магнитов. В результате анализа пространственного распределения индукции магнитного поля установлено, что в межсполюсном рабочем объеме сепаратора образуется достаточно интенсивное магнитное поле с высоким значением градиента индукции. Отмечена целесообразность использования результатов исследования для выбора рациональных конструктивных параметров магнитной системы и определения силовых характеристик сепаратора. Библ. 11, рис. 8.

Ключевые слова: магнитный сепаратор, постоянный магнит, магнитное поле, метод конечных элементов.

Introduction. In recent years, high-coercive rareearth permanent magnets (PM) based on $\mathrm{NdFeB}$ (neodymium-iron-boron) are widely used in electromechanical devices for technological purposes (separators, feeders). At a relatively low cost, they have a high residual magnetic flux density $B_{r}$ (up to $B_{r}=1.44 \mathrm{~T}$ ); Characterized by temperature stability at temperatures up to $150{ }^{\circ} \mathrm{C}$; have a small volume per unit of energy; are resistant to the influence of demagnetizing fields $[1,2]$.

The variety of shapes, structural layouts and directions of PM magnetization allows creating new magnetic systems of electromechanical devices with the necessary topology of the magnetic field in working gaps. Electromechanical devices with PM can not only successfully compete with their electromagnetic counterparts, but also have extended functionality.

Analysis of literary data and problem definition. Analysis of the distribution of the magnetic field is an important stage in the design of separation devices based on PM. The nature of the distribution of the magnetic field in the working gaps of such devices depends essentially on the configuration of the magnetic system, which should be optimized for the mass of the PM.

In high-performance magnetic separators, as shown in $[3,4]$, mainly magnets of cylindrical or annular shape are used. In [3], a mathematical model is proposed for the distribution of the scalar magnetic potential created in the surrounding space by a cylindrical or circular PM. This model is based on the representation of a PM in the form of an equivalent solenoid, contains in explicit form PM parameters and can be used to analyze the external field of magnets in a homogeneous medium.

In [5] experimental studies of the magnetic field induction distribution in the simplest case - for single and paired magnetic elements in various modules of magnetic separators were performed. The possibility and practical expediency of using the superposition principle to establish the resulting induction characteristic of the field between opposing magnetic elements is shown to replace the actual simulation with the calculated one.

The results of experimental studies of the distribution of magnetic forces in the working zones of cylindrical magnetic systems of drum separators are presented in [6]. The influence of the main operating parameters on the performance of a high-gradient separator with a PM was investigated in [7].

Much of the publication is devoted to the use of computer simulation to study magnetic fields created by PM in the working gaps of magnetic separators.

(C) J. Gerlici, I.A. Shvedchikova, I.V. Nikitchenko, J.A. Romanchenko 
In [8] the results of calculation and introduction of the drum separator on the PM are presented. To solve the problem of choosing the optimal parameters of the magnetic system, a finite element modeling package for partial differential equations FEMLAB was used. In this case, a plane-parallel analogy was considered, which, taking into account the length of the separator, sufficiently well reflects the real spatial picture of the field distribution.

A new design of a magnetic separator with transversely magnetized disk permanent magnets was proposed in [9]. Calculation of the magnetic field is performed using the finite element method. It is shown that the largest values of the force factor (about $\mathrm{T}^{2} / \mathrm{m}$ ) are reached in regions with the highest magnetic field density.

As the analysis of publications [3-9] has shown, the calculation of the magnetic field in the working interpolar gaps of magnetic separators is a rather complex task, which for most configurations of magnetic systems has not been solved analytically until now, and the experimental methods are rather laborious. When developing new designs of magnetic separators to obtain information on the distribution of magnetic field induction in working gaps, it is expedient to use numerical calculations with the use of appropriate computer programs.

The goal of the work is to investigate the influence of the configuration of the magnetic system (shape and dimensions of the PM) on the spatial distribution of the magnetic flux density in the working area of the magnetic separator of a new design.

Material and results of investigations. Investigation of the influence of the configuration of the magnetic system on the topology of the magnetic field was carried out for a new design of a disk separator [10, 11] proposed by the authors of the paper. The disk separator is designed to extract ferromagnetic inclusions from granular media conveyed by belt conveyors. In the operating mode, the device is installed above the surface of the bulk material. The magnetic system of the separator includes annular magnets arranged along the Archimedes spiral at equal distances from each other with alternating polarity of the poles in the radial direction and in the direction of the spiral deployment. In this case, the same distance is also maintained between adjacent coils of the spiral forming its pitch. With this configuration of the magnetic system, conditions are created for self-cleaning of the working surface of the disk from the extracted ferromagnetic inclusions, which greatly simplifies the process of unloading them without stopping the separation process.

Fig. 1 shows a fragment of a spiral magnetic disk separator system containing four annular magnets, indicating the main design parameters: $\delta$ - air gap; $a$ - transverse dimension (width) of the magnet; $b-$ distance between adjacent coils of the spiral; $t$ - thickness of the magnets (assumed to be unchanged, equal to $t=12.5 \mathrm{~mm}$ ).

The magnetic field in the system with PM in the absence of an electric current is described by a system of Maxwell equations, which in the magnetostatic approach has the form [10]:

$$
\begin{gathered}
\nabla \times \boldsymbol{H}=0, \\
\nabla \cdot \boldsymbol{B}=0,
\end{gathered}
$$

where $\boldsymbol{H}$ is the vector of the magnetic field strength; $\boldsymbol{B}-$ is the vector of the magnetic flux density.

Equation of state for permanent magnets:

$$
\boldsymbol{B}=\mu_{0} \mu_{r} \boldsymbol{H}+B_{r},
$$

where $\mu_{r}, B_{r}$ are the relative value of the magnetic permeability and the residual magnetic flux density of the $\mathrm{PM}$, respectively; $\mu_{0}=4 \pi \cdot 10^{-7} \mathrm{H} / \mathrm{m}$ is the magnetic constant.

Equation of state for ferromagnetic materials and surrounding medium (air):

$$
\boldsymbol{B}=\mu_{0} \mu_{r} \boldsymbol{H},
$$

where $\mu_{r}$ is the relative value of the magnetic permeability for the ferromagnetic material and air $\left(\mu_{r}=1\right)$, respectively.

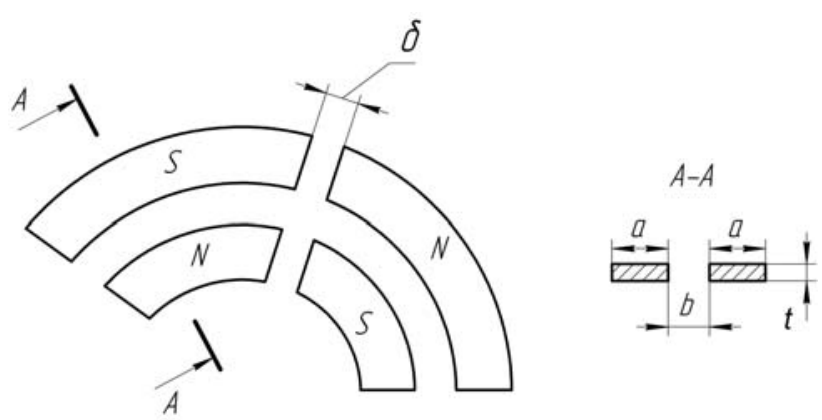

Fig. 1. A fragment of the separator magnetic system indicating main dimensions

At the first stage, the effect of the shape of the cross section of the PM on the distribution of the induction of the magnetic field in the air gap was investigated. The task was to determine the shape of the PM cross section, at which the mass of the magnetic system is minimal, and the induction created in the air gap is maximum. Four shapes of the cross section of the poles were considered (the width of the magnets $a$ was assumed to be $a=67.5 \mathrm{~mm}$ ): rectangular (Fig. 2,a); rectangular with oblique angles (Fig. 2,b); trapezoidal (Fig. 2,c); spherical (Fig. 2,d).
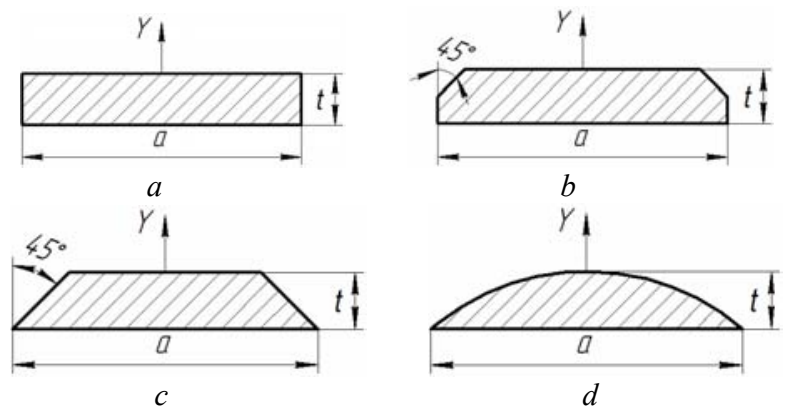

Fig. 2. The investigated shapes of the cross-section of poles: $a$ - rectangular; $b$ - rectangular with oblique angles; $c$ - trapezoidal; $d$-spherical

The solution of the problem defined for investigating the effect of the shape of the cross section of a PM is performed by the numerical finite element method in twodimensional formulation using the Elcut software package. The following characteristics of the high- 
coercive magneto-hard material of the $\mathrm{NdFeB}$ type were set: the relative magnetic permeability $\mu_{r}=1.06$; residual magnetic flux density of magnets $B_{r}=1.2 \mathrm{~T}$ (vertical component directed along the $Y$ axis, see Fig. 2), coercive force $H_{c} \geq 995 \mathrm{kA} / \mathrm{m}$. As the boundary conditions at the outer boundaries of the computational domain, the condition of magnetic isolation was used. In Fig. 3, as an example, a geometric model is shown (Fig. 3,a) with a mesh of finite elements applied to it and a simulation result in the form of a field pattern (Fig. 3,b) for a PM with a rectangular cross-sectional shape.
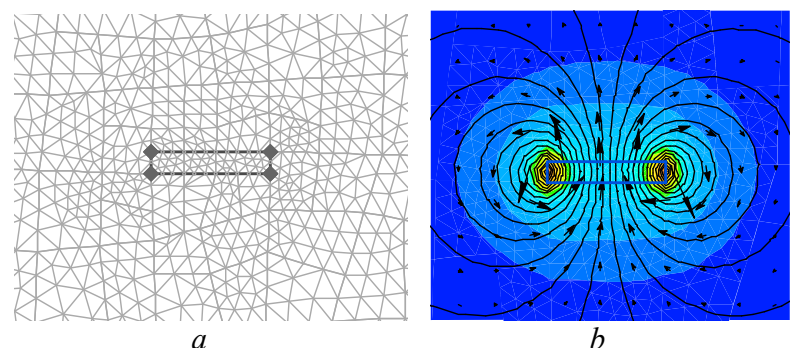

Fig. 3. Modeling of PM with rectangular cross-sectional shape: $a$-geometrical model; $b$ - results of modeling

Determination of the magnetic flux density module $B_{i}$ ( $i=1, \ldots, 4$, where 1 corresponds to a rectangular, 2 - rectangular with oblique angles, 3 - trapezoidal and 4 - spherical shape of the cross section PM, respectively) was carried out along the $Y$ axis (see Fig. 2) at distances from the surface of the magnets from 0 to $100 \mathrm{~mm}$ in increments of $5 \mathrm{~mm}$. Fig. 4 shows the data of the ratio of the values of the magnetic flux density modules $B_{i}$ at selected points for all four forms of the cross sections of the poles to the corresponding values of the magnetic flux density module $B_{l}$ for PM with a rectangular crosssectional shape.

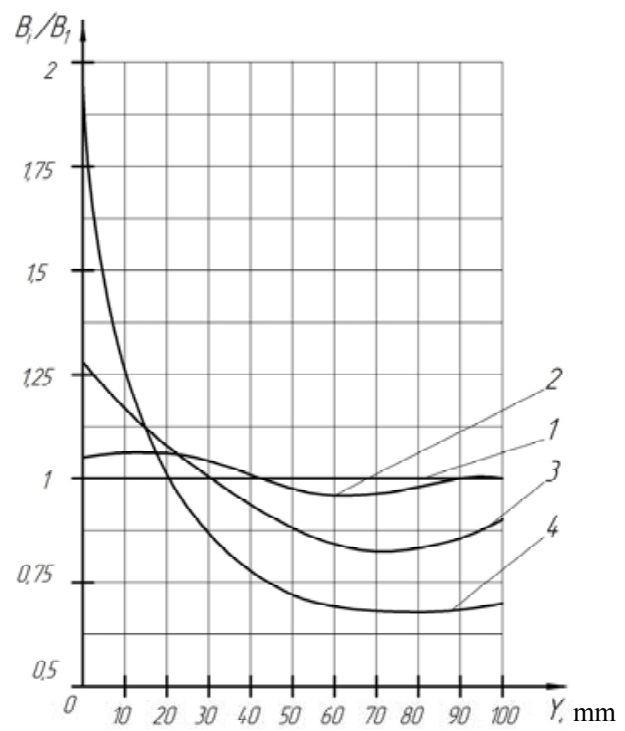

Fig. 4. Comparison of the ratios of the magnetic flux density modules $B_{i} / B_{l}$ for PM with different cross-sectional shapes:

1 - rectangular; 2 - rectangular with oblique angles; 3 - trapezoidal; 4 - spherical

As can be seen from Fig. 4, at small distances from the surface of the PM $(0 \leq Y \leq 15 \mathrm{~mm})$, the maximum values of the magnetic induction are provided by spherical (curve 4 in Fig. 4) and trapezoidal (curve 3 in Fig. 4) PM. They also gain considerably in weight in comparison with magnets of rectangular cross section (for the same length of magnets): the calculated mass of a spherical magnet is $32 \%$, and the trapezoidal magnet is $19 \%$ less than the calculated mass of a PM with a rectangular cross-sectional shape.

However, at large distances ( $Y \geq 20 \mathrm{~mm}$ ), where the separation process usually occurs, the intensity of the magnetic field, produced by the magnets of the spherical and trapezoidal sections, decreases significantly. In this case, the magnets with a rectangular (curve 1 in Fig. 4) and rectangular with oblique angles (curve 2 in Fig. 4) form nearly uniform magnetic field intensity, not significantly different in mass (no more than 5\%).

In view of the foregoing, further studies should recommend the use of circular PM with a rectangular cross-sectional shape. They provide the highest indices of magnetic induction in working air gaps at the required distances. In addition, magnets of this form are widely represented in the catalogs of companies engaged in the sale of PM.

At the second stage, in order to substantiate the basic geometric dimensions of the magnetic system of a given configuration, the magnetic field distribution for two three-dimensional models of the magnetic system was calculated (Fig. 5) with the same calculated PM masses (16.28 kg): model 1 (Fig. 5, $a): \delta=25 \mathrm{~mm}, a=67.5 \mathrm{~mm}$, $b=51.7 \mathrm{~mm}$; model 2 (Fig. $5, b$ ): $\delta=50 \mathrm{~mm}$, $a=25.5 \mathrm{~mm}, b=19.0 \mathrm{~mm}$. Fig. 5 also shows the characteristic points at which measurements were taken (model 1 has 39, and model 2 has 119 characteristic points, respectively).
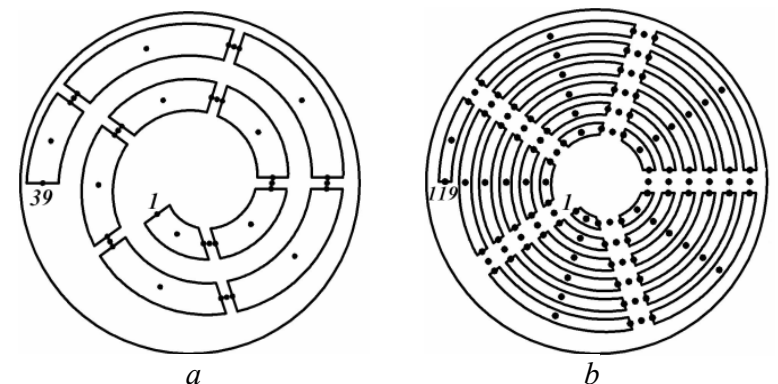

Fig. 5. Magnetic systems with indication of characteristic points: $a$-model $1 ; b$-model 2

The study of the regularities of the spatial distribution of the magnetic flux density in the working area of a new-design magnetic separator is performed by the finite element method using the COMSOL Multiphysics 3.5a application package.

A three-dimensional geometric model 1 of a magnetic system with a mesh of finite elements applied to it is shown in Fig. 6,a. For a ferromagnetic disk on which a PM is installed, it is assumed that the relative magnetic permeability $\mu_{r}$ of the disk material is constant $\left(\mu_{r}=1000\right)$. The geometric dimensions of the disk (diameter $-700 \mathrm{~mm}$, thickness $-15 \mathrm{~mm}$ ) are selected, based on the dimensions of the conveyor systems most often used in practice. Fig. $6, b$ is a fragment of the pattern of the distribution of magnetic flux density lines in the 
gap between the annular poles of the PM. Fig. $6, b$ shows that the lines of force thicken in the vicinity of the gaps and somewhat rarefy within the magnets.
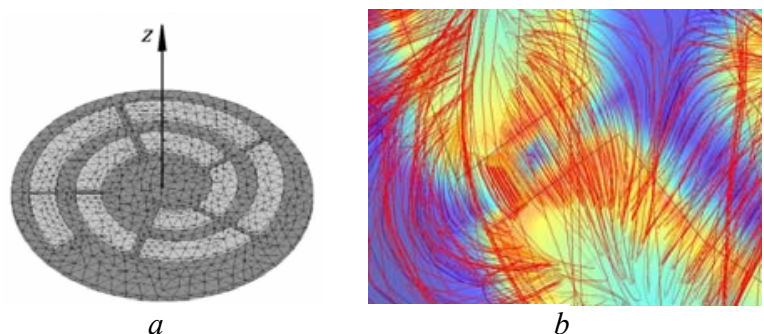

Fig. 6. 3D modeling of the magnetic system:

$a$-geometrical model; $b$ - results of modeling

Some results of modeling, in particular change of the magnetic flux density module $B$ along lines $a-a^{\prime}$ and $b-b^{\prime}$ (shown in Fig. 7) for the model 1 at $Z=0 \mathrm{~mm}$ are shown in Fig. 8.

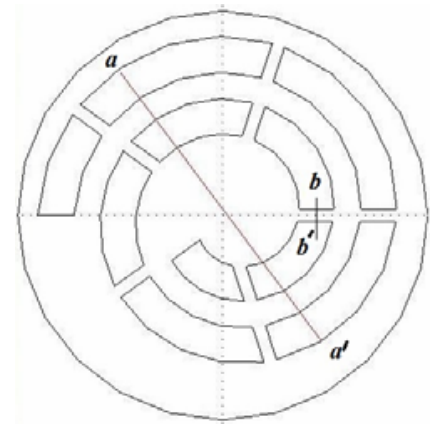

Fig. 7. Lines along which measurement of the magnetic flux density module $B$ is carried out

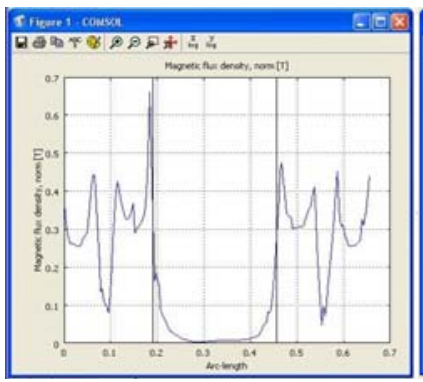

$a$

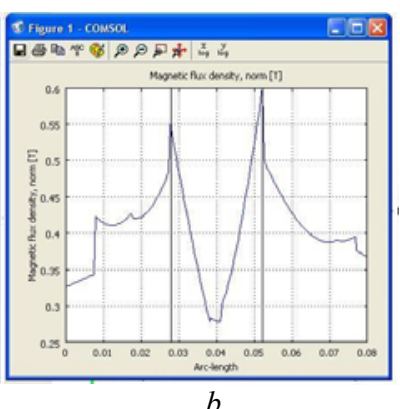

Fig. 8. Distribution of the magnetic flux density on the interface between media «PM - air gap»:

$a$ - in radial direction (along line $a-a^{\prime}$ );

$b-$ in the direction of unfolding the spiral (along line $b-b^{\prime}$ )

As can be seen from Fig. 8, $a$ very large difference is observed between the maximum $\left(B_{\max }\right)$ and minimum $\left(B_{\min }\right)$ values of the magnetic flux density at the surface of the magnets at $Z=0 \mathrm{~mm}$, both in the radial direction (Fig. 8,a) and in the direction of the spiral (Fig. 8,b). The maximum value of the magnetic flux density $B$ is at the points lying on the interface between media «PM - air gap», and the minimum - at points located in the middle of the magnet and air gap, respectively. On the magnet surfaces (at $Z=0 \mathrm{~mm}$ ), there is a sufficiently strong magnetic field: $B_{\max }=0.76 \mathrm{~T}$ (for model 1) and $B_{\max }=0.80 \mathrm{~T}$ (for model 2) - at the boundary PM - air gap; $B_{\max }=0.31 \mathrm{~T}$ (for model 1 ) and $B_{\max }=0.55 \mathrm{~T}$ (for model 2) - in the middle of the magnet pole. The greatest difference $\Delta B$ between the maximum $B_{\max }$ and the minimum $B_{\min }$ values of the magnetic flux density is also observed at $Z=0 \mathrm{~mm}$ at the boundary PM - air gap and is: $0.34 \mathrm{~T}$ for model 1 and $0.47 \mathrm{~T}$ for model 2 .

Thus, using computer modeling, the influence of the configuration of the magnetic system (cross-sectional shape and PM dimensions) on the spatial distribution of the magnetic flux density in the working area of the magnetic separator on the PM has been carried out.

\section{Conclusions.}

Investigation of the influence of the shape of the cross-section of the PM on the distribution of the magnetic flux density in the air gap of the device made it possible to establish the following regularities:

- at small distances from the surface of the PM $(0 \leq Y \leq 15 \mathrm{~mm})$, the maximum values of magnetic flux density are provided by a PM with a spherical and trapezoidal cross-sectional shape with a much lower calculated mass of the PM in comparison with the PM of a rectangular section;

- at relatively large distances from the surface of the poles of the PM $(Y \geq 20 \mathrm{~mm})$, where the separation process takes place, the intensity of the magnetic field produced by the magnets of the spherical and trapezoidal sections is significantly lower than for magnets with a rectangular and rectangular cross-sectional shape. In this case, magnets with rectangular and rectangular crosssectional shapes with cross-sectional shapes create approximately equal intensity fields, differing in mass by no more than $5 \%$.

An analysis of the spatial distribution of the magnetic flux density in the working area of the magnetic separator of the new design showed that a strong magnetic field $\left(B_{\max }=0.76 \ldots 0.8 \mathrm{~T}\right)$ with a high gradient of magnetic flux density is formed in the interpolar working volume. The highest degree of field inhomogeneity takes place at the media interface «PM - air gap».

The obtained results can be used to select rational design parameters of the magnetic system and determine the power characteristics of the separator.

\section{REFERENCES}

1. Furlani E. Permanent Magnet and Electromechanical Devices: Materials, Analyses and Application. New York Academic Press, 2001, p. 518. doi:10.1016/B978-0122699511/50005-X.

2. Strnat K.J. Modern Permanent Magnets for Application in Electro-Technology. Proceedings of the IEEE, 1990, vol. 78, no. 6, pp.923. doi: 10.1109/5.56908.

3. Bulyzhev E.M., Menshov E.N., Dzhavahija G.A. Modeling of the field permanent magnet. Proceedings of the Samara Scientific Center of the Russian Academy of Sciences, 2011, vol.13, no.4, pp.106-110. (Rus).

4. Bulyzhev E.M., Menshov E.N. Mathematical modeling of the field a permanent magnet. Electricity, 2010, no. 9. pp. 65-69. (Rus).

5. Sandulyak A.A., Ershov D.V., Oreshkin D.V., Sandulyak A.V. Characteristics of Magnetic Field Induction inside a Module of a Magnetic Separator. Vestnik MGSU, 2013, no.5, pp. 103-111. (Rus).

6. Kilin V.I. Kilin S.V. By choosing the pole pitch of the magnetic separator systems for dry processing. Obogashchenie Rud, 2008, no.6, pp. 14-18. (Rus). 
7. S. Zeng, W. Zeng, L. Ren, D. An, H. Li. Development of a high gradient permanent magnetic separator (HGPMS) Minerals Engineering, Feb. 2015, vol.71, pp. 21-26. doi: 10.1016/j.mineng.2014.10.009.

8. Lozin A.A., Arsenjuk V.M., Petrivskij Ya.B. Information and analytical technologies at calculation and modeling stationary magnetic systems in the construction of separators based on permanent magnets. Gornyi Zhurnal, 2004, no.5. (Rus). Available at: http://www.prodecolog.com.ua/pdf/gorec.pdf.

9. S. Nedelcu, J. H. P. Watson. Magnetic separator with transversally magnetised disk permanent magnets. Minerals Engineering, May 2002, vol.15, no.5, pp. 355-359. doi: 10.1016/s0892-6875(02)00043-2.

10. Shvedchikova I.A., Zemziulin M.A. Research of the magnetic field distribution in the magnetic disk separator with spiral-type system. Electromechanical and energy saving systems, 2013, no.2(22), part 2, pp. 18-24. (Rus).
11. Shvedchikova I.O., Romanchenko J.A. Diskoviy magnitniy separator [Disc magnetic separator]. Patent UA, no. 110206, 2016. (Ukr).

Received 21.01.2017

Juraj Gerlici ${ }^{1}$, Professor, Dr. Ing.,

I.A. Shvedchikova ${ }^{2}$, Doctor of Technical Science, Professor,

I.V. Nikitchenko ${ }^{2}$, Postgraduate Student,

J.A. Romanchenko ${ }^{2}$, Postgraduate Student,

${ }^{1}$ University of Žilina, Žilina, Slovak Republic,

1, Univerzitná, SK 01026 Žilina, Slovak Republic, phone 421(41)513 2550,

e-mail: juraj.gerlici@fstroj.uniza.sk

${ }^{2}$ Volodymyr Dahl East Ukrainian National University,

59-a, pr. Central, Severodonetsk, 93400, Ukraine, phone +380990448571,

e-mail: ishved@i.ua,inna.mia.lg@gmail.com

How to cite this article:

Gerlici J., Shvedchikova I.A., Nikitchenko I.V., Romanchenko J.A. Investigation of influence of separator magnetic system configuration with permanent magnets on magnetic field distribution in working area. Electrical engineering \& electromechanics, 2017, no.2, pp. 13-17. doi: 10.20998/2074-272X.2017.2.02. 